\title{
A PATEMIZAÇÃO COMO RECURSO DE PERSUASÃO EM REPORTAGEM PUBLICADA NA FOLHA DE SÃO PAULO REFERENTE À PROFESSORA HELEY
}

\section{The "emotion in discourse" as a persuasion resource in a publishment published in folha de são paulo about the teacher Heley}

\author{
Francisco Herbert da Silva ${ }^{1}$ \\ Demócrito de Oliveira Lins ${ }^{2}$ \\ João Benvindo de Moura ${ }^{3}$
}

RESUMO: Neste artigo, analisamos a patemização e o(s) sujeito(s) da linguagem numa reportagem publicada na Folha de São Paulo, referente à professora Heley. Para a realização da pesquisa, apoiamo-nos em teóricos, como: Charaudeau (2001; 2008), destacando, assim, o pathos e a teoria dos sujeitos da linguagem; Perelman (2014), por discutir acerca da persuasão em construções discursivas, no que tange ao caráter persuasivo da reportagem, visando, principalmente a categoria pathos, utilizada para transformar e conquistar a adesão de seu auditório. A pesquisa é qualitativa e interpretativa, sendo nosso corpus composto por uma reportagem publicada na versão online do jornal Folha de São Paulo, em 07 de outubro de 2017. A análise nos permitiu constatar que as tópicas enunciativas mais recorrentes na reportagem, foram: "a tópica da proteção de desamparados; a superação da morte do filho; a superação da morte do pai; o espírito altruísta e a tópica de certa autoridade moral.

Palavras-chave: Persuasão. Folha de São Paulo. Sujeitos da linguagem. Pathos.

ABSTRACT: In this article, we have analyzed the "emotion in discourse" and the language subjects on a publishment of Folha de São Paulo newspaper, which it refers the professor Heley. To this research construction, we supported in theorics such as: Charaudeau $(2001 ; 2008)$, highlighting, therefore, the pathos and the theory of language subjects; Perelman (2014), to argue about the perssuation in discousive construction, because of persuasive construction of the publishment, in order to, mainly the pathos category used to change and conquer her auditorium attention.

${ }^{1}$ Graduado em Letras - Português (UESPI). Especialista em Língua Portuguesa (UESPI). Aluno do Mestrado Acadêmico em Letras da Universidade Estadual do Piauí (UESPI). Email: herberty silva@hotmail.com

${ }^{2}$ Graduado em Letras - Português (UESPI). Especialista em Língua Portuguesa (UESPI). Aluno do Mestrado Acadêmico em Letras da Universidade Estadual do Piauí (UESPI). Email: E-mail: democritolins@hotmail.com

${ }^{3}$ Doutor em Estudos Linguísticos (UFMG). Docente do Programa de Pós-Graduação em Letras (PPGEL) da Universidade Federal do Piauí (UFPI). E-mail: ibenvindo@ufpi.edu.br

Cadernos Cajuína, V. 4, N. 1, 2019, p. 265 - 281.

ISSN: 2448-0916 
The research is qualitative and interpretative, its corpus is composed by a publishment published in a online version of Folha de São Paulo newspaper, on October 7th, in 2017. Summary, we verified which enuciative topics, nowadays, in publishment, they were: proctetion topic of homeless; overcoming their son death; overcoming their father death; altruistic energy and the topic of moral authority.

Keywords: Persuasion. Folha de São Paulo. Language subjects. Pathos.

\section{CONSIDERAÇÕES INICIAIS}

Este artigo corresponde parte de estudos teóricos e analíticos de uma pesquisa de Mestrado que tem como aparato teórico, a Análise do Discurso (doravante $A D$ ) e a Argumentação, destacando dentre outras noções, o pathos e os sujeitos da linguagem, os quais se manifestam de diferentes formas, pois o contexto de realização do discurso molda a forma como fazemos uso da linguagem, independente de como será realizada. Dessa forma, a escolha do gênero e do objeto de estudo se deu principalmente, por entender que a reportagem é um gênero argumentativo/persuasivo, que em sua construção argumentativa são utilizados diferentes recursos, em especial, o pathos e a relação contratual. Assim, a pesquisa objetiva analisar a presença do efeito patêmico atrelado aos sujeitos da linguagem numa matéria publicada na Folha de São Paulo, que tem como referente a Heley, professora que tentou impedir o incêndio na creche de Janaúba (MG).

Para desenvolver nossa análise, apoiamo-nos na proposta de Charaudeau (2001), que apresenta um quadro sistemático da relação contratual. Além disso, recorremos a Charaudeau (2008), por discutir a categoria de pathos, visando, assim, o caráter persuasivo da reportagem, que, consequentemente, está relacionado com o propósito comunicativo do Sujeito Comunicante, sensibilizando o Sujeito Destinatário, demostrando emoções, sentimentos e afetos. A partir da análise discursiva da reportagem, foi possível evidenciar a recorrência das estratégias argumentativas, com o objetivo de persuadir os interlocutores da Folha Online, pois o enunciador da reportagem recorre a Tia da Professora Heley, externando um caráter sentimental e emocional ao relatar a trajetória de Heley.

Assim sendo, a relação contratual contribuiu na identificação da patemização no texto, tendo em vista, a intencionalidade do jornalista e a aceitabilidade dos 
interlocutores que leram a matéria. O Sujeito Comunicante, representado pelo Jornal, se apropria de vários recursos, em especial, o pathos para demostrar a triste situação em que passou a creche diante do incêndio e a morte de alunos e de professores. É possível perceber que o efeito de patemização sensibiliza os leitores da Folha de São Paulo.

Além das orientações da $A D$, também buscamos apoio nos estudos argumentativos de Perelman; Olbrechts-Tyteca (2014), quando asseveram que a persuasão é uma ação realizada pelo auditório, visando a adesão dos interlocutores em relação a defesa da tese.

Diante do que foi exposto, a organização interna do artigo traz reflexões sobre os sujeitos da linguagem e da relação contratual, além de destinar uma seção para se discutir acerca dos efeitos realizados pelo pathos na reportagem. Em seguida, observar-se-á o conceito de persuasão, partindo do pressuposto de que o pathos é uma estratégia argumentativa. Assim sendo, como forma de contextualizar, para se falar de persuasão, foi preciso apoiarmos nossa análise também, nos estudos argumentativos, em especial, aqueles de perspectivas argumentativas e discursivas. Por fim, propor-se-á uma análise com intentando a identificação do efeito patêmico atrelado à relação contratual na reportagem.

\section{CONTRATO DE COMUNICAÇÃO NA MÍDIA}

Durante muito tempo, os estudos da linguagem foram considerados a partir de enfoque estruturalista, como perspectiva de análise. Essa consolidação de análise estrutural foi determinada tomando por base, a abordagem sistemática do Estruturalismo, vertente consolidadora da Linguística como ciência. Além do Estruturalismo, destacamos também, a Teoria Gerativista de Chomsky, que analisava a linguagem a partir da premissa dos falantes ideais, adotando a concepção inativista da linguagem. Assim sendo, tanto o Estruturalismo quanto o Gerativismo desconsideravam o sujeito falante da língua no ato de comunicação, pois, não era objetivo de tais abordagens estudar o funcionamento, mas a estrutura da língua. Sumariamente estamos apresentando o percurso histórico dos estudos linguísticos, de modo a compreender o tratamento dado ao sujeito da linguagem.

Diante da perspectiva formalista de análise linguística, é possível apresentar abordagens de estudos em que se priorizavam o sujeito como o ser da Cadernos Cajuína, V. 4, N. 1, 2019, p. 265 - 281.

ISSN: 2448-0916 
comunicação. Para Charaudeau (2001), a teoria apresentada por Benveniste apregoa que "a teoria da Enunciação, a presença dos responsáveis pelo ato de linguagem, suas identidades, seus estatutos e seus papeis, são levados em consideração" (CHARAUDEAU, 2001, p. 27). A perspectiva enunciativa, mesmo que ainda de forma tímida, redimensionou o olhar dos estudos linguísticos, partindo da concepção de que o sujeito é visto com responsável pela prática enunciativa, passando, assim, a ser objeto de investigação, ocupando papel de destaque na teoria da enunciação. A partir dos estudos enunciativos, é possível depreender o papel dos sujeitos discursivos no ato de enunciação, principalmente, quando Benveniste (2006), no capítulo "Aparelho formal da linguagem", apresenta o Eu/ Tu e uma não pessoa, que seria o "Ele". Além disso, para o autor, no uso da linguagem também é necessário considerar o tempo e o espaço da enunciação, definido como o "aqui" e o "agora".

Além dos estudos formalistas, a ousada abordagem da enunciação, proporcionou uma variedade de estudos, levando em consideração o sujeito, um ser responsável pelo ato de linguagem, dimensões dialógicas, interacionistas e cognitivas. Vale ressaltar que, além das abordagens ora citadas, destacamos também, a contribuição da Pragmática para os estudos linguísticos, pelo fato de estudar a língua em uso, priorizando o sujeito falante, que mesmo sem levar em consideração a teoria dos sujeitos da linguagem, enfoca as condições de produções dos performativos, principalmente, porque o valor performativo não está na língua, mas nas condições de produção.

Considerando o contexto de investigação da linguagem, exposto aqui de forma introdutória e que contribuiu para os estudos de Patrick Charaudeau, mais especificamente a Teoria Semiolinguística, destacamos a seguir, os aspectos que caracterizam a perspectiva de estudo do autor. Assim, é possível entender que o olhar da Teoria Semiolinguística se debruçou, essencialmente sobre a ligação entre os fatos referentes à linguagem em relação à certos fenômenos psíquicos e sociais. Essa teoria visa um caráter interdisciplinar, com o intuito de relacionar outras áreas de estudo da linguagem.

Desse modo, a Teoria Semiolinguística tem como objeto de estudo o fenômeno linguagueiro, conforme Corrêa-Rosado (2014). É interessante frisar que o ato de linguagem agrega uma configuração semiológica da linguagem, tanto explícita quanto implícita, podendo ser vista, a partir das relações sociais em que um 
discurso foi produzido. Logo, entendemos que "o ato de linguagem significa não somente pela sua configuração semiológica visível, mas também pelos saberes que são acionados pelos sujeitos durante os processos de produção e interpretação deste ato" (CORRÊA-ROSADO, 2014, p. 03).

A Teoria Semiolinguística considera também, os conhecimentos que estão fora da linguagem, entendendo os fatos da linguagem a partir de conhecimentos sociais acionados cognitivamente. Corrêa-Rosado (2014), argumenta que a produção do sentido acontece na relação entre 0 ato de linguagem e a intenção estabelecida através do fenômeno discursivo da enunciação. Reforçamos ainda, que o sentido se constrói a partir de uma gama de informações, seja por meio da linguagem, seja por meio dos conhecimentos sociais.

Conforme frisamos anteriormente, convém apresentar, de forma introdutória, a concepção argumentativa de Patrick Charaudeau, quando afirma que "a fim de haja argumentação é necessário ainda que os indivíduos partilhem um contrato intelectual baseado principalmente aos contextos sócio históricos" (PROCÓPIO, 2017 , p. 240). É notório que no processo de argumentação, os envolvidos compartilham conhecimentos que estão intrinsicamente relacionados com os aspectos sociais, havendo assim, intenções que partem do orador ao propor uma tese, influenciando os interlocutores com argumentos ou estratégias argumentativas que intentam persuadir ou convencer o auditório, destacando principalmente, a reportagem, fonte desta investigação.

Diante das perspectivas teóricas apresentadas, no ato de linguagem, os sujeitos estão inseridos em circuitos comunicativos, sistematizando o contrato comunicacional da linguagem. Assim sendo, Charaudeau (2001, p. 28), afirma que:

\footnotetext{
$O$ ato de linguagem é um fenômeno que combina o dizer e o fazer. $O$ fazer é o lugar da instância situacional que se auto - define pelo espaço que ocupam os responsáveis deste ato [...]. O dizer é o lugar da instância discursiva que se auto - define como uma encenação da qual participam seres de palavra [...]. Esta dupla realidade do dizer e do fazer nos leva a considerar que 0 ato de linguagem é uma totalidade que se compõe de um circuito externo (fazer) e de um circuito interno (dizer), indissociáveis um do outro.
}

Corroborando a discussão do autor, percebemos que o ato de linguagem é representativo de práticas sociais, em que os sujeitos são seres psicossociais. $\mathrm{O}$ contrato de comunicação é dividido por seres que contribuem com a produção e a 
interpretação dos enunciados, considerados na relação contratual, denominados de circuito externo (Fazer), representado pelo Sujeito Comunicante (EUc) e o Sujeito Interpretante (TUi) e também, os pertencentes ao circuito interno (Dizer), compreendido pelo Sujeito Enunciador (EUe) e o Sujeito destinatário (TUd), ambos representam os efeitos de discurso, centrado exclusivamente nas estratégias discursivas. Desse modo, apresenta-se o quadro criado por Charaudeau (2001), que sintetiza as relações contratual.

Figura 01: Representação do ato de linguagem

Fazer - situacional

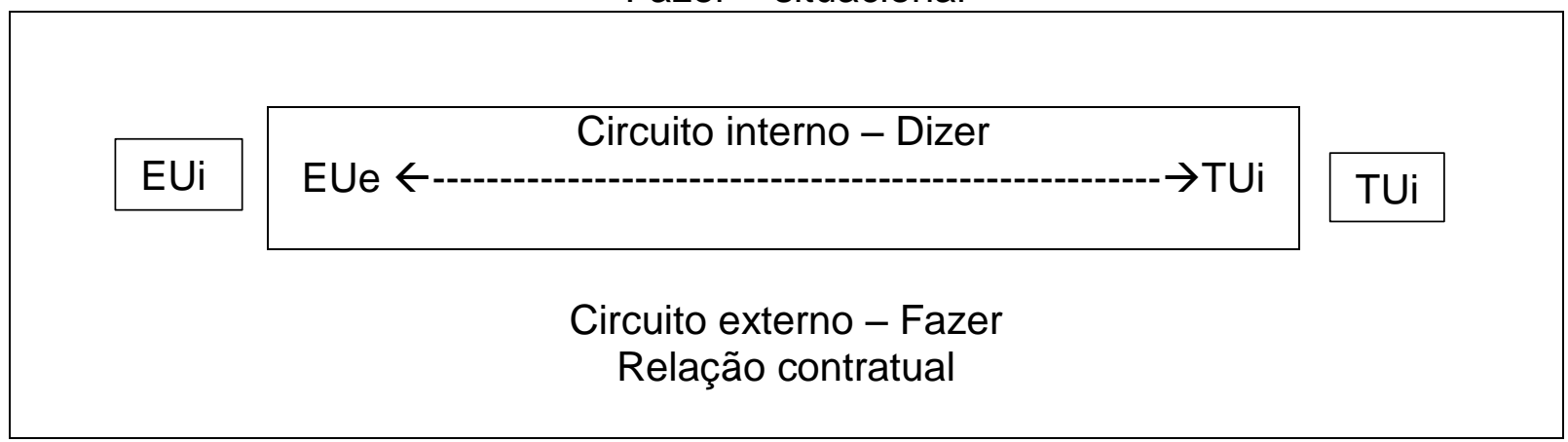

Fonte: Charaudeau (2001, p. 29)

A figura acima, que representa 0 ato de linguagem, sintetiza a relação contratual entre os sujeitos de comunicação. Como forma de organização, a Semiolinguísitca propõe, tanto um conceito de linguagem, quanto a organização da posição dos sujeitos do ato de linguagem, assim, dividido em dois circuitos; o circuito externo, inerente do "Fazer", constituído basicamente do material psicossocial do ato, a situação de comunicação em que se fazem presente dois sujeitos, considerados de psicossociais, denominados de parceiros da comunicação, como o Sujeito Comunicante (EUc) e o Sujeito Interpretante (TUi). Além desse, há também, o circuito interno, visto como o material verbal do ato de linguagem. Nesse circuito, temos dois outros sujeitos, chamados de protagonistas do dizer, representado pelo Sujeito enunciador (EUe) e pelo Sujeito destinatário (TUd).

Dessa forma, o sujeito comunicante é o responsável pela relação contratual, como aquele que participa da produção, instituído como o locutor, que toma a palavra, testemunhando uma realidade. Assim, é através do (EUc), que podemos projetar dois outros sujeitos, aqueles que estão dentro do circuito interno, o (EUe) e o (TUd), o primeiro é responsável pelo papel da comunicação no ato de linguagem, pondo em cenas as intenções do (EUc); já o (TUd) é uma imagem depreendida pelo 
(EUc). Assim sendo, o (TUi) é responsável pela condução do processo de interpretação, assim como (EUc) é o sujeito que testemunha uma realidade qualquer; essa mesma característica é atribuída ao (TUi). É importante ressaltar que o ato de linguagem pode ser considerado assimétrico, do ponto de vista da produção e da interpretação, pois, não temos como prejulgar o (EUe) e o (TUd) em relação a natureza do (EUc) e, muito menos, da reação estabelecida pelo (TUi).

\section{O PATHOS E A MÍDIA}

Os jogos de linguagens representados por diversos discursos, em especial, as práticas sociais visam à intencionalidade, sejam eles, condicionados explícita ou implicitamente. Entendemos também, que ao fazer uso das práticas linguageiras, várias são as maneiras de manifestações dos sujeitos, sendo que essas representações são determinadas, às vezes, por sentimentos ou emoções, representativos de estratégias que levam os interlocutores a adesão de uma tese.

Assim, acreditamos que um determinado acontecimento referente às práticas linguageiras e condicionadas às práticas sociais resultam na identificação e observação da patemização, visto que "é pelo fato das emoções se manifestarem em um sujeito em função de alguma coisa que esse sujeito se faz representar enquanto tal. Digamos que seja por isso que essas emoções podem ser ditas representacionais" (CHARAUDEAU, 2008, p. 241).

Diante do exposto, a patemização é determinada por sentimentos, emoções, que os sujeitos emitem através de práticas de linguagens. Os efeitos patêmicos estão ligados a crenças, possibilitando, assim, apresentar argumentos, numa tentativa de justificar um determinado acontecimento. $O$ discurso das emoções é definido em trocas sociais, pois, o efeito de patemização é uma estratégia que busca persuadir interlocutores, a partir de uma tese. Assim, o orador/enunciador recorre de forma empírica, aos seus conhecimentos, demostrando sensação, típica da percepção do sujeito. O enunciador é capaz de transformar a opinião de um grupo/interlocutor específico, fazendo uso de sentimentos e emoções.

Afirmamos ainda que "um discurso que visa a produzir uma emoção é, por si refutável se for observável que, por exemplo, podemos replicar a alguém que tenta nos sensibilizar "você pode se fazer de vítima, mas você não me comover". (CHARAUDEAU, 2008, p. 242). Assim, percebemos que a prática de patemização 
nem sempre leva o auditório a aceitar aquilo que defendemos, quando o enunciador recorre a estratégia do pathos. Às vezes, produzimos emoções, demostramos sentimentos, que podem não ser suficientes para que haja convencimento daquilo que se revela aos outros. Para a construção da argumentação, o que está sendo dito, pode ser motivo de refutação, motivo de contestação, mesmo quando o orador faz uso de prática subjetiva, demostrando sensibilidade com visada argumentativa.

A persuasão ocorre quando o orador apresenta uma tese, e esta é aceita pelo interlocutor. $\mathrm{O}$ ato de persuadir leva o sujeito a uma ação, a partir do diálogo entre orador e o auditório. Dessa forma, a persuasão acontece quando fazemos uso de estratégias argumentativas, principalmente, quando objetivamos influenciar interlocutores específicos, conforme Perelman; Olbrechts-Tyteca (2014). Diante disso, é possível perceber que o efeito da patemização é um recurso de persuasão, mas que pode ser refutável, dependendo das trocas sociais em que estão envolvidos os sujeitos responsáveis, demostrando sentimentos e emoções.

Considerando a discussão sobre pathos, acreditamos que as manifestações patêmicas estão relacionadas com o propósito do sujeito comunicante, estabelecidas em trocas interacionais. Dessa forma, é possível argumentar que:

O sujeito então recorre a estratégias discursivas que tendem a tocar a emoção e os sentimentos do interlocutor - ou do público - de maneira a seduzir ou, ao contrário, Ihe fazer medo. Trata-se de um processo de dramatização que consiste em provocar a adesão passional do autor atingindo suas pulsões emocionais. (CHARAUDEAU, 2008, p. 245).

Corroborando com o autor, depreendemos que o efeito de patemização, sumariamente, está determinado por relações sociais, por sentimentos e emoções, possibilitando a sedução ou não, dos interlocutores. O efeito patêmico também pode ser visto como a dramatização de uma situação, visando a simulação, com o objetivo de impressionar ou levar o outro a aderir a opinião apresentada. Assim sendo, o pathos se refere à prática subjetiva do sujeito, sendo possível a adesão, quando fazemos uso do pathos como estratégia argumentativa.

Além disso, Silva (2013, p. 258) comungando do pensamento apresentado por Charaudeau (2008) afirma que "falar de estratégias de pathos é falar do uso que o político faz dos sentimentos, paixões e emoções para seduzir os membros da instância cidadã a apoiarem suas pretensões e projetos políticos". É evidente que o 
efeito de patemização compreende às estratégias usadas pelo orador/enunciador em troca linguagueira, assim, essa prática tem a pretensão de que um determinado público seja comovido com as representações aludidas através dos efeitos patêmicos. O recurso de persuasão produz no interlocutor um posicionamento que Ihe seja favorável, com vistas a situação apresentada na comunicação, resultando assim, em efeitos emocionais atribuídos a um acontecimento.

A estratégia de pathos pode produzir ou não emoções no interlocutor, pois devemos considerar os fatores sociais na produção do efeito patêmico. $\mathrm{Na}$ construção do efeito patêmico, é possível afirmar que:

[...] um discurso pode produzir um efeito emocional conforme a natureza do universo de crença do público a que é destinado, conforme a natureza da encenação discursiva e conforme o posicionamento do interlocutor ou do público em relação ao universo de crenças convocado. (SILVA, 2013, p. 258)

Assim, o autor busca apoio na discussão de Charaudeau (2008), alguns critérios que sistematizam a produção de um efeito patêmico, a saber: natureza de crença do interlocutor, natureza de produção discursiva, postura/ posicionamento do interlocutor diante das emoções determinadas.

Moura (2010, p. 1014) ao analisar um editorial do Jornal Meio Norte argumenta que "as emoções suscitadas não acontecem por acaso, não consistem apenas em simples sensações. Elas são da ordem do intencional, tendo em vista que remetem a uma base cognitiva, estão a serviço de um agir para alcançar um objetivo" [...]. Diante disso, entendemos que o orador age propositalmente em relação ao auditório, levando em consideração os conhecimentos inerentes dos sujeitos envolvidos, assim como a intenção do orador. Acreditamos também, que os interlocutores vivenciam as possíveis emoções, levando-os à adesão daquilo que está sendo proposto.

\section{O PATHOS COMO RECURSO DE PERSUASÃO}

Diante da categoria do pathos é necessário elencar as contribuições dos estudos da argumentação, principalmente, a perspectiva que temos de persuasão para os estudos argumentativos. Para tanto, recorremos a proposta de Perelman; Olbrechts-Tyteca (2014), que apresentam algumas noções de persuasão e de 
convencimento. Eles acreditam se tratarem de perspectivas diferentes, afirmando inclusive, que persuadir vai além do que vem a ser o convencer, visto que podemos convencer alguém sobre algo, mas necessariamente, a pessoa pode não ser persuadida. Além disso, Moura; Teixeira (2015, p. 161), acreditam que "todos os públicos, auditórios assimilam, além de fatos e verdades, presunções”. Assim sendo, na organização argumentativa, os envolvidos no processo de comunicação assimilam que a tese é necessária para que haja à persuasão, havendo assim, acordo na validação das presunções, tendo em vista, a recorrência de argumentos que contribuem para o efeito persuasivo.

Para uma melhor compreensão dessa distinção sobre persuadir e convencer, destacamos o seguinte exemplo:

[...] que tal pessoa, convencida do perigo de mastigar muito rápido, nem por isso deixará de fazê-lo, porque se isola o raciocínio em que se baseia essa convicção de todo um conjunto. Esquece-se, por exemplo, que tal convicção pode colidir com outra convicção, a que nos afirma que há ganho de tempo em comer mais depressa. (PERELMAN; OLBRECHTS-TYTECA, 2014, p. 30-31).

A persuasão é constituída como a adesão do auditório particular, por exemplo, uma pessoa pode estar convencida de que comer rápido traz prejuízo à saúde, mas, necessariamente nem todos param de comer rápido, mesmo sabendo os riscos. Já a convicção, na visão dos autores, compreende o conhecimento de uma determinada tese, tendo em vista os fatos e acontecimentos. Paralelamente a essa discussão, os autores afirmam que a persuasão corresponde a "ação" e a convicção compreende a "inteligência". Entendemos também, que o sujeito pode apreender um determinado conhecimento, que pode não ser suficiente para uma mudança, que seria a persuasão ou ação decorrida da inteligência.

Além disso, é interessante destacar as contribuições quando "o sujeito desenvolve estratégias de argumentação de acordo com suas intenções em influenciar seu interlocutor" (PROCÓPIO, 2017, p. 240). Dependendo da tese que se pretende defender, os sujeitos recorrem às múltiplas possibilidades que contribuem para o processo argumentativo, levando o auditório a aderir à premissa. Diante das concepções apresentadas acerca do que vem a persuadir e convencer, é possível entender que todo ser humano está sujeito a acreditar em fatos e acontecimentos, mas essas informações não supõem transformação ou persuasão. É possível 
concluir ainda, que a persuasão compreende a natureza particular do auditório. A convicção resulta na adesão por parte de um auditório acerca de determinada tese ou crença. Diante dos postulados, percebemos que as categorias da argumentação apresentam conceitos próximos, e, mesmo sendo distintos, se complementam junto aos acordos estabelecidos entre os atores envolvidos no processo de comunicação.

\section{A ENCENAÇÃO PATÊMICA A PARTIR DA MORTE DE UMA PROFESSORA}

Analisamos os aspectos patêmicos presentes em uma reportagem publicada em 07 de outubro de 2017, pela Folha de São Paulo, intitulada “'Heroína’, professora que protegeu crianças perdeu filho afogado", que trata de um incêndio provocado pelo vigia de uma creche de Minas Gerais, resultando assim, na morte de oito crianças e dois adultos.

Em primeiro lugar, partimos da concepção de que o mundo real tal como o concebemos, na realidade, não existe. A realidade, na verdade, é produto da percepção cultural de um enunciador, que realiza escolhas lexicais, a partir da diversidade que sua(s) língua(s) Ihe oferece $(\mathrm{m})$ para poder apresentar a sua "realidade", tal como ele a concebe. Assim sendo, aceitamos que o fato ocorrido na Creche Criança Inocente, em Minas Gerias, poderia ser apresentado de diversas maneiras, dependendo de vários fatores, dentre os quais, se destacam as condições de produção e o propósito comunicativo do enunciador; assim, a escolha das expressões linguísticas utilizadas para categorizar e qualificar as entidades e eventos do fato sucedido dependerá sobretudo, de tais fatores.

Em segundo lugar, recordamos que os efeitos patêmicos ocorrem quando,

O sujeito falante recorre a estratégias discursivas que tendem a tocar
a emoção e os sentimentos do interlocutor - ou do público - de
maneira a seduzir ou, ao contrário, lhe fazer medo. Trata-se assim,
de um processo de dramatização que consiste em provocar a adesão
passional do outro, atingindo suas pulsões emocionais.
(CHARAUDEAU, 2008, p. 245)

Desse modo, verificando as diversas semioses da linguagem presentes na reportagem, percebendo que a parte imagética introdutória do texto já traz explícitas as tópicas da "dor" e da "angústia", o que pode ser exemplificado a partir de questionamentos, como: Quem não se sensibiliza ao ver um caixão, que talvez 
evoque alguma situação particular relacionada a morte de algum ser querido e quem não se angustia diante da impossibilidade de ação perante tal fenômeno iniludível?, que tendem a materializar as pulsões do Sujeito Destinatário. Percebemos que o Sujeito Enunciador mobiliza saberes de crença do público a que é destinado, relacionados à morte; assim, considerando a crença presente na memória discursiva, no imaginário social, relacionada ao caráter trágico da morte, ou seja, supondo que o seu Sujeito Enunciatário não vê a morte com bons olhos, como a passagem para uma vida melhor, e sim como algo trágico, o Sujeito Enunciador vai construindo seu relato.

Um discurso pode produzir um efeito emocional conforme a natureza do universo de crença do público a que é destinado, conforme a natureza da encenação discursiva e conforme o posicionamento do interlocutor ou do público em relação ao universo de crenças convocado. (SILVA, 2013, p. 258)

Retomando, em certa medida, a questão da "não realidade da realidade" e ao fato de que o enunciador apresenta a sua versão de realidade sob a influência de diversos fatores (aspectos sócio-histórico-culturais, condições de produção, etc.), de acordo com sua intenção comunicativa, aceitamos que, no caso da matéria, poderse-ia apresentar o fato sucedido de diversas formas. No entanto, o sujeito enunciador, por exemplo, decide adotar a professora Heley de Abreu Silva Batista como protagonista, e representá-la discursivamente como "heroína". Deixamos à modo de reflexão e provocação, a possível relação entre tal escolha, por parte do Sujeito Enunciador, tanto da forma de apresentação do fato sucedido, como a representação discursiva de Helley e as datas comemorativas que se celebrariam na semana seguinte à publicação da notícia (Dia das Crianças e Dia dos Professores).

A tese, assim, é apresentada: a professora foi uma heroína. A partir de então, depreendemos os vários argumentos para sustentá-la, partindo das características da professora, a saber: a proteção dos desamparados (as crianças), a superação de situações trágicas e traumáticas, o espírito altruísta, a posse de certa autoridade moral. A seguir apresentaremos trechos da reportagem grifados em itálico seguidos das identificações das tópicas enunciativas. Assim, o enunciador passa a apontar sequencialmente uma série de fatos para justificar toda a cena enunciativa: 
a) A proteção de desamparados: "'Heroína', professora protegeu crianças [...]". Temos no imaginário social que a principal função de um herói é a proteção de um ente, seja ele coletivo (geralmente o é), seja ele individual.

b) A superação da morte do filho: "[...] Mas na verdade ela deu à luz pela quarta vez: um dos filhos morreu aos 5, afogado, após cair numa piscina de um clube."; "Foi ela que deu força e segurou as pontas para o marido e para a mãe"'”. Qualquer sujeito é afetado emocionalmente pela perda de um filho, independentemente do lugar social que ocupe. Assim sendo, Heley, apesar de haver perdido seu filho de 5 anos, seguiu adiante, como uma heroína.

c) A superação da morte do pai: "[...] Como também segurou [as pontas] quando o pai morreu, do coração, há 12 anos, nas contas da tia."

d) O espírito altruísta: ““Não media esforços por ninguém. Não tinha tempo para ela, só para os outros. Se um filho ficava doente, ela botava no carro e ia embora para o hospital de Montes Claros, sozinha, não importando a hora, não pensava duas vezes", lembra Doralice". Além disso, morreu tentando salvar as crianças: "quando um professor assume uma sala de aula, dá a vida pelos seus alunos [...]"; "Heley de Abreu Silva Batista morreu, [...] após tentar salvar as crianças da creche em que trabalhava".

e) A posse de certa autoridade moral: "Era bem-quista também pelos amigos dos meninos [...]; frequentava a Igreja de Nossa Senhora da Aparecida, onde dava cursos de batizado e noivado e organizava encontro de casais - seu filho mais velho é coroinha e tem dois primos padres". Além disso, Heley era "casada e mãe e três filhos". Sabemos que na cultura ocidental atual, ser casado e mãe (ou pai) de família, ainda, é sinônimo de possuir um certo status social, digno de respeito. Não é à toa que algum criminoso ao ser detido e, no ato de sua condução à cárcere, enuncie: "não façam isso comigo; sou pai de família", claramente, querendo implicitamente dizer que o respeitem.

Perder uma pessoa com todas essas características heroicas, realmente toca a emoção e os sentimentos de qualquer sujeito. Há certas pistas linguísticas que revelam, em certa medida, crenças e pontos de vista do Sujeito Enunciador. Por exemplo, este assume a visão de que o magistério não é profissão, e sim, um sacerdócio: "[...] diz que aprendeu esse ensinamento nos primeiros anos de 
sacerdócio em Montes Claros, [...]". A unidade linguística destacada evoca, de antemão, uma espécie de sacrifício a ser realizado pelo que executa tal função, que, por sua vez, suscita determinadas emoções. Percebemos, ademais, a presença da tópica da "esperança", e seu oposto, a "angústia": "[...] Às 23h, a esperança acabou - para desespero do marido, com quem deixa os três filhos do casal, de 15, 12 e 1 ano e 3 meses" (grifo nosso). Finalmente, concebendo a argumentação como ato de "provocar ou aumentar a adesão dos espíritos às teses que se apresentam a seu assentimento" (PERELMAN; OLBRECHTS-TYTECA, 2014, p. 50), vemos ainda que o Sujeito enunciador lança mão de várias declarações de Doralice, que, além de tia e pessoa muito próxima à Heley, era também, uma espécie de mestre inspiradora, e portanto, possuía autoridade para falar sobre a sobrinha.

Notamos como todos os enunciados transcritos revelam uma estreita relação entre as emoções e a racionalidade, fazendo assim, emergir aspectos, como a dor, a alegria, a esperança, a angustia e o desespero. Além do efeito patêmico, é evidenciado no decorrer da reportagem que o enunciador recorre a estratégias de persuasão tipificadoras da demonstração de sentimentos e emoções diante do acontecimento. Assim, outras classificações, como a Relação Contratual, proposta por Charaudeau (2001), contribuem simultaneamente para o caráter comunicacional, uma forma de organizar os sujeitos evolvidos na comunicação, apresentando ações típicas das práticas sociais, contribuindo para o efeito patêmico.

Dessa forma, quando recorremos ao Contrato Comunicacional, fica mais claro, que os recursos utilizados pelo Sujeito Comunicacional (EUc), representado pelo jornal Folha de São Paulo, na pessoa dos jornalistas Thiago Amâncio e Zanone Fraissat, autores da matéria, recorrem ao Sujeito Enunciador (EUe) (Tia da Professora), relatando a trajetória e o sentimento em relação a carreira profissional da sobrinha. A Tia afirma que a sobrinha, durante a vida de professora, sempre foi engajada na profissão, argumentando os sofrimentos passados por Heley, presenciando a morte do pai morrendo de infarto, além do filho, que morreu afogado.

Assim sendo, como forma de sensibilizar os Sujeitos Destinatários, neste caso, os leitores do Jornal Folha de São Paulo, o EUc recorre ao EUe, a Tia da professora, por conhecer de perto a trajetória de vida da sobrinha. Talvez, se o jornal apenas relatasse o acontecimento, sem a inserção da fala da Tia, não teria o mesmo efeito patêmico. É possível perceber que as categorias dialogam entre si, estão separadas apenas como forma de didatizar as informações discursivas. 
O efeito patêmico presente na reportagem é um recurso de persuasão, o EUc utiliza-se dessa estratégia como forma de conseguir a adesão de uma tese, de que a professora foi uma das pessoas que tentou barrar o incêndio no Centro de Educação Infantil Gente Inocente, em Janaúba (MG). Diante disso, no próprio título, que é a: "Heroína, professora que protegeu crianças perdeu filho afogado" o pathos é identificado. Nele, o EUc se posiciona em relação ao acontecimento, demostrando de forma explícita, o efeito patêmico, denominando-a de heroína diante de tantos problemas que a professora já passou, em especial, a morte do filho afogado.

Também, no subtítulo é possível evidenciar a sensibilidade, em que o EUc proporciona sentimentos ao Sujeito Interpretante, pessoas que, possivelmente leem as matérias da Folha Online, através do subtítulo, que é "casada e mãe de 3 filhos, docente tentou barrar ataque de vigia em Minas, mas morreu com 90\% do corpo queimado". Observamos também, o posicionamento do EUc no trecho em destaque, o qual apresenta características de uma pessoa que realmente lutou para impedir o incêndio na creche, lutou que morreu com a maior parte do corpo queimada.

\section{CONSIDERAÇÕES FINAIS}

Neste artigo, foi possível identificar as contribuições da patemização para construção da argumentação em uma reportagem publicada no Jornal Folha de São Paulo. Assim, acreditamos que a patemização é uma estratégia argumentativa, com caráter persuasivo, que visa promover à adesão dos sujeitos destinatários em relação aos efeitos sensíveis, as emoções e aos sentimentos.

Partimos, em primeiro lugar, da concepção de que a linguagem pode representar a realidade de diversas formas, pois as operações linguageiras, de acordo com o caráter multifacetado da linguagem, possibilitam ao usuário, utilizá-las da melhor forma, haja vista que o enunciador ao se apropriar da linguagem, intencionalmente, tenta manipular os interlocutores, em específico, o público leitor do Jornal Folha de São Paulo, usando de estratégias argumentativas, com destaque para a patemização, com fins de persuadir os interlocutores, partindo da gravidade do acontecimento relatado na reportagem.

Em segundo lugar, adotamos a concepção de que a patemização proposta por Charaudeau (2008), oportuniza observar os efeitos que sensibilizam os leitores do jornal, pois os jornalistas recorreram aos relatos disponibilizados pela Tia de Cadernos Cajuína, V. 4, N. 1, 2019, p. 265 - 281.

ISSN: 2448-0916 
Heley, detalhando principalmente, os momentos de sofrimentos e de dedicação da professora, sendo reconhecida pelas ações e denominando-a de "heroína". $\mathrm{Na}$ análise, foi possível evidenciar algumas tópicas enunciativas que conduziram a investigação, sendo que, na reportagem foram apresentadas situações que causam emoções, podendo ser vistas nos relatos sobre as mortes do filho e do pai de Heley, bem como, quando é enunciado que a professora teve $90 \%$ do corpo queimado, tentando salvar as crianças.

As tópicas mais recorrentes, foram: a proteção de desamparados, que pode ser observada quando, na reportagem, se afirma que Heley morreu tentando proteger as crianças no momento do incêndio na creche; a superação da morte do filho, uma vez que era mãe de quatro filhos, sendo que um morreu afogado, tipo de morte que mexe com o psicológico de qualquer pessoa. Também foi apresentado na reportagem que, Heley presenciou a morte do pai, causa da morte, infarto. Além disso, foi possível perceber o espírito altruísta da professora, quando foi relatado que sempre estava disposta ajudar, visto que morreu tentando salvar a vida das crianças. Considerando as ações realizadas pela professora Heley, evidenciamos também, uma certa autoridade moral, pois era uma pessoa que frequentava a igreja, oferecendo voluntariamente cursos de batizados e de noivos.

Portanto, neste artigo, foi possível identificar a presença do efeito patêmico, como um recurso argumentativo/persuasivo atrelado à relação contratual. Diante do corpus e do objeto de estudo, constatamos que o jornal buscou informações advindas da tia da professora, com a finalidade de sensibilizar os interlocutores, principalmente, porque relatam situações difíceis em que a professora enfrentou como profissional e como ser social. Com isso, observamos que, mesmo com tanta dificuldade, a professora, segundo o jornal, é uma heroína.

Concluímos também, que os sujeitos da linguagem, naturalmente fazem uso de recursos argumentativos e persuasivos, como por exemplo, o pathos, objetivando influenciar e promover à adesão dos interlocutores a tese. Além disso, ressaltamos que essa análise não esgota as possibilidades de se fazerem presentes outras categorias argumentativo/discursivas, no entanto, para este estudo selecionamos o pathos e relação contratual como forma de guiar a investigação. 


\section{REFERÊNCIAS}

AMÂNCIO, Thiago; FRAISSAT, ZANONE. 'Heroína', professora que protegeu crianças perdeu filho afogado. Folha de São Paulo, São Paulo, 07 out. 2017.

Cotidiano, p. 1/2. Disponível em: < http://acervo.folha.uol.com.br/fsp/2017/10/08/871/ >. Acesso em: 30 nov. 2017.

BENVENISTE, Émile. Problemas de Linguística geral II. 2. ed. Campinas: Pontes, 2006.

CORREAA-ROSADO, Leonardo Coelho. Teoria Semiolinguística: alguns pressupostos. UNINCOR, Belo Horizonte, v. 05, n. 2, 2014, p. 01-18.

CHARAUDEAU, Patrick. Uma teoria dos sujeitos da linguagem. In: MARI, Hugo; MACHADO, Ida; MELLO, Renato de (Orgs.). Análise do Discurso: fundamentos e práticas. Belo Horizonte: NAD/FALE/UFMG, 2001. p. 23-38.

Pathos e discurso político. In: MACHADO, Ida Lúcia; MENEZES, William; MENDES, Emília (Orgs.). As emoções no discurso. Rio de Janeiro: Lucerna, 2008. p. $240-251$.

MOURA, João Benvindo de. "Piauí: é feliz quem vive aqui" - efeitos de patemização na mídia. In: Anais do II Fórum Internacional de Análise do Discurso. Rio de Janeiro, 2010. p. 1008-1015.

; TEIXEIRA, Virna Pereira. A opção pelos pobres: a persuasão através de recursos argumentativos nos discursos do Papa Francisco. In: MOURA, João Benvindo de; BATISTA JÚNIOR, José Ribamar Lopes; LOPES, Maraisa (Orgs.). Discurso, memória e inclusão social. Recife: Pipa Comunicação, 2015. p. 155179.

PROCÓPIO, Mariana Ramalho. As estratégias argumentativas do presidente Obama para a construção de imagens do Brasil. In: MOURA, João Benvindo de; BATISTA JÚNIOR, José Ribamar Lopes; LOPES, Maraisa (Orgs.). Sentidos em disputa: discursos em funcionamento. Teresina: EDUFPI, 2017. p. 239-257.

PERELMAN, Chaim; OLBRECHTS-TYTECA, Lucie. Tratado da Argumentação: a nova retórica. Tradução Maria Ermantina de Almeida Prado Galvão. São Paulo: Martins Fontes, 2014.

SILVA, José Otacílio da. Charaudeau. In: OLIVEIRA, Luciano Amaral (Org.).

Estudos do discurso: perspectiva teóricas. São Paulo: Parábola, 2013. p. 235-260. 